\title{
Antioxidant Activity of Silymarin/Hydroxyapatite/Chitosan Nano Composites - An In Vitro Study
}

Research Article

\author{
S. Aravind Kumar ${ }^{1}$, Ramachandra Prabhakar ${ }^{2}$, N. Raj Vikram³ ${ }^{3}$ SP Saravana Dinesh ${ }^{4}$, S Rajeshkumar ${ }^{5 *}$
}

${ }^{1}$ Research Scholar, Department of Orthodontics, Dr. MGR Educational and Research Institute, Chennai, India.

${ }^{2}$ Dean, Professor \& Head, Department of Orthodontics, Thai Moogambigai Dental College and Hospital, Chennai, India.

${ }^{3}$ Professor, Department of Orthodontics, Thai Moogambigai Dental College and Hospital, Chennai, India.

${ }^{4}$ Professor, Department of Orthodontics, Saveetha Dental College and Hospital SIMATS, Saveetha University, Chennai, India.

${ }^{5}$ Nanobiomedicine Lab, Department of Pharmacology, Saveetha Dental College and Hospital, SIMATS, Saveetha University, Chennai, India.

\section{Abstract}

\begin{abstract}
Nanoparticles and nano-composites are major advanced materials used in many medical and dental applications. In this present investigation, we have prepared silymarin, chitosan and hydroxyapatite based nanocomposite using magnetic stirring. The prepared nanocomposite characterized using UV-vis spectroscopic analysis. The free radical scavenging activity of prepared nanocomposites was tested using DPPH assay. The results are statically analyzed and the antioxidant results are good for nanocomposite materials. Based on the results the prepred nanocomposites may used in various dental applications.
\end{abstract}

Keywords: Nanocomposites; Antioxidant; Chitosan; Silymarin; HAP.

\section{Introduction}

The oxygen utilization characteristic in cell development leads to the age of a progression of receptive oxygen species (ROS). ROS include free radicals such as superoxide anion radicals $\left(\mathrm{O}^{2}\right), 2$ hydroxyl radicals $(\mathrm{OH} \bullet)$ and non free-radical species such as hydrogen peroxide $\left(\mathrm{H}_{2} \mathrm{O}_{2}\right)$ and single oxygen [1-3].

ROS at physiological concentration might be needed for typical cell work. They are likewise equipped for damaging critical biomolecules, for example, nucleic acids, lipids, proteins, polyunsaturated unsaturated fats and carbs and may cause DNA damage that can prompt changes $[4,5]$.

Silymarin, a known standardized extract obtained from seeds of Silybummarianum (Milk Thistle) is widely used in treatment of several diseases. Silymarin, a plant derived flavonoid, which is named benzopyranone, is secluded from the products of the soil of the milk thorn (Silymarinmarianum) is a combination of three primary parts: silibinin, silydianine and silychristine. It has been known for its hepatoprotective antibacterial, antiallergic, antimutagenic, antiviral, hostile to neoplastic, antithrombotic special- ists and vasodilatory activities. One of the significant issues with respect to silymarin is that it could be acknowledged as a natural compound [6-9].

Hydroxyapatite (HA )possess significant mechanical strength, biocompatibility, low resorbability, osteoconductivity, HA is extensively used in orthopedic and dentistry as metallic implant coating and cavity filling material and also, as the key constituent in toothpaste and mouth washes to remineralize artificial carious lesions [10].

Chitin, especially its deacetylated form, and chitosan are well known marine biopolymers, having many applications in the food industry, agriculture, biotechnology, cosmetics, medicine. The reactive functional groups of chitosan include an amino group and both primary and secondary hydroxyl groups at C-2, C-3, and C-6 positions, respectively. The biological activities of chitosan and its derivatives correlated with their structures and physicochemical properties $[11,12]$. The green synthesized nanoparticles such as silver, selenium, zinc oxide and copper etc. shows very good antioxidant, antimicrobial and many more biomedical applications [13-20].

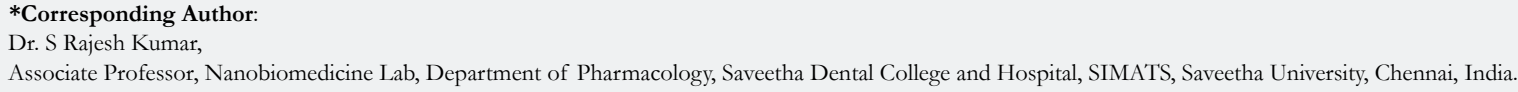

Copyright: S Rajeshkumar ${ }^{\circ}$ 2021. This is an open-access article distributed under the terms of the Creative Commons Attribution License, which permits unrestricted use, distribution and reproduction in any medium, provided the original author and source are credited. 
The aim of the present study is to investigate the antioxidant potential of Silymarin Hydroxyapatie and Chitosan Nanoparticles.

\section{Materials and Methods}

\section{Preparation of Nanocomposite}

The different concentration of chitosan, silymarin and hydroxyapatite was mixed in the beaker and kept in magnetic stirrer for $48 \mathrm{~h}$. the colour change was observed and scanning process was done using UV-vis spectroscopy from $200 \mathrm{~nm}$ to $700 \mathrm{~nm}$.

\section{Antioxidant activity of Chitosan, HAP, silymarin and Nano- composites}

The antioxidant activity of nanocomposites descrbed shortly, $1 \mathrm{~mL}$ DPPH solution was added to all tubes. To that silymarin, HAP, chitosan and nanocomposites pellet solution was added in the range of $10 \mu \mathrm{L}, 20 \mu \mathrm{L}, 30 \mu \mathrm{L}, 40 \mu \mathrm{L}, 50 \mu \mathrm{L}$. And $50 \%$ methanol solution was added in the range of $1990 \mu \mathrm{L}, 1980 \mu \mathrm{L}, 1970$ $\mu \mathrm{L}, 1960 \mu \mathrm{L}, 1950 \mu \mathrm{L}$.
The tubes were incubated at dark condition for 15 -20 minutes. Photometry was taken for all tubes at $517 \mathrm{~nm}$ and the readings were recorded.

\section{Results and Discussion}

The figure 2 shows the UV-vis spectroscopic analysis of nanocomposite prepared using Hydroxyaptite nanoparticles, bioactive compound and chitosan nanoparticles based nanocomposites. The peaks individual silymarin/chitosan and silymarin/HAP shows single peaks and broad peaks confirm the nanocomposite formation.

The figure 3 clearly shows the antioxidant activity of chitosan, HAP and silymarin materials. The increased concentration of materials shows good activity. The figure 4 shows the antioxidant activity of HAP/Chitosan/silymarin nanocomposite with good $\%$ of inhibition. It clearly shows the higher activity of free radical scavenging, when compared with remaining nanoparticles and bioactive compounds individually. The nanoparticles are very actively involved antioxidant activity in in vitro and in vivo [21-22].

Figure 1. Visual observation of formation of Silymarin/HAP Chitosan nanocomposites.

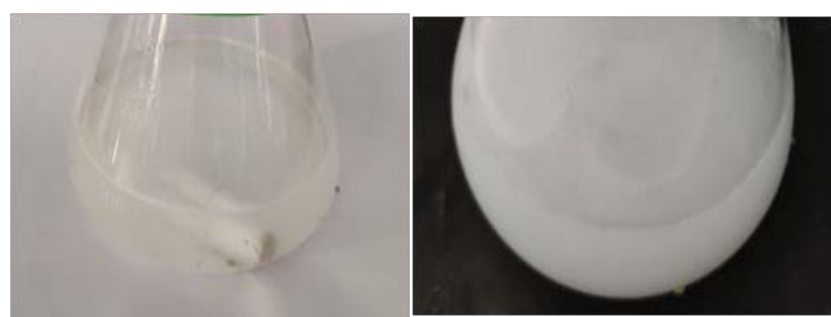

Figure 2. UV-vis spectroscopy analysis of silymarin chitosan, silymarin mediated HAP nanoparticles and Silymarin/HAP/ chitosan nanocomposites.
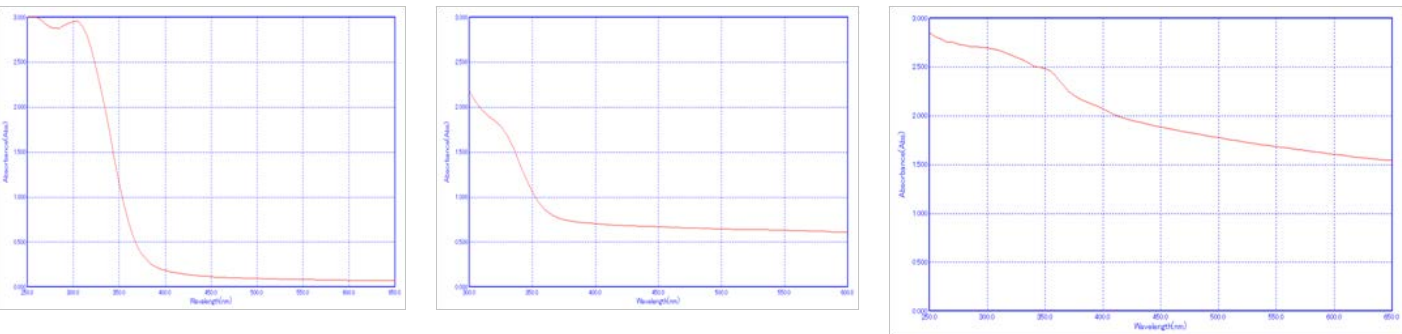

Figure 3. Antioxidant activity of Zinc oxide, silymarin, chitosan materilas.
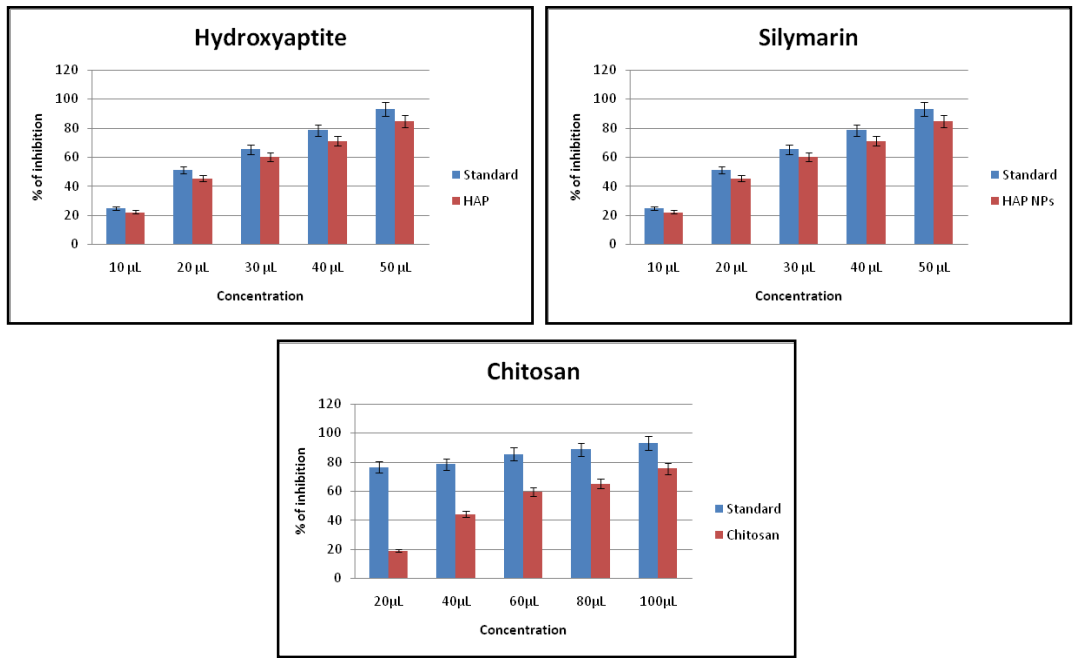
Figure 4. Antioxidant activity of nanocomposite.

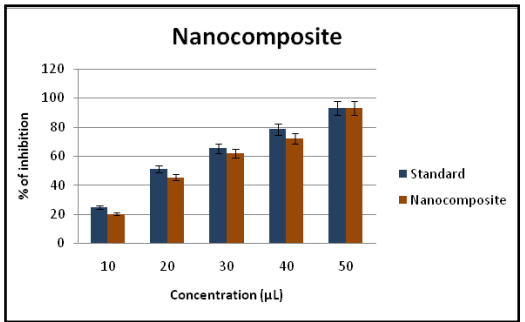

\section{Conclusion}

The nanocomposite synthesized using bioactive compound silymarin, biopolymer chitosan and hydroxyapatite shows very good free radical scavenging activity using DPPH assay. Based on our results we are planning to use this nanocomposite in the orthodontic applications.

\section{References}

[1]. Farombi EO, Fakoya A. Free radical scavenging and antigenotoxic activities of natural phenolic compounds in dried flowers of Hibiscus sabdariffa L. Mol Nutr Food Res. 2005 Dec; 49(12): 1120-8. PMID: 16254885.

[2]. Gülçin I, Oktay M, Küfrevioğlu OI, Aslan A. Determination of antioxidant activity of lichen Cetraria islandica (L) Ach. J Ethnopharmacol. 2002 Mar; 79(3): 325-9. PMID: 11849836.

[3]. Gülçin I. Antioxidant and antiradical activities of L-carnitine. Life Sci. 2006 Jan 18; 78(8): 803-11. PMID: 16253281.

[4]. Halliwell B, Gutteridge JM. Role of free radicals and catalytic metal ions in human disease: an overview. Methods Enzymol. 1990; 186: 1-85. PMID: 2172697.

[5]. Gülçın İ, Oktay M, Kıreçcı E, Küfrevıoğlu Öİ. Screening of antioxidant and antimicrobial activities of anise (Pimpinella anisum L.) seed extracts. Food chemistry. 2003 Nov 1; 83(3): 371-82.

[6]. Fraschini F, Demartini G, Esposti D. Pharmacology of silymarin. Clinical drug investigation. 2002 Jan; 22(1): 51-65.

[7]. Kren V, Walterová D. Silybin and silymarin--new effects and applications. Biomed Pap Med Fac Univ Palacky Olomouc Czech Repub. 2005 Jun; 149(1): 29-41. PMID: 16170386

[8]. Abascal K, Yarnell E. The many faces of Silybum marianum (milk thistle): part 2-clinical uses, safety, and types of preparations. Alternative \& Complementary Therapies. 2003 Oct 1; 9(5): 251-6.

[9]. Toklu HZ, Tunali-Akbay T, Erkanli G, Yüksel M, Ercan F, Sener G. Silymarin, the antioxidant component of Silybum marianum, protects against burn-induced oxidative skin injury. Burns. 2007 Nov; 33(7): 908-16. PMID: 17521818

[10]. Pepla E, Besharat LK, Palaia G, Tenore G, Migliau G. Nano-hydroxyapatite and its applications in preventive, restorative and regenerative dentistry: a review of literature. Ann Stomatol (Roma). 2014 Nov 20; 5(3): 108-14. PMID: 25506416.

[11]. FU HY, SHIEH DE, HO CT. Antioxidant and free radical scavenging activities of edible mushrooms. Journal of food lipids. 2002 Mar; 9(1): 35-43.

[12]. Park PJ, Je JY, Kim SK. Free radical scavenging activities of differently deacetylated chitosans using an ESR spectrometer. Carbohydrate Polymers. 2004 Jan 1; 55(1): 17-22.

[13]. Kamath KA, Nasim I, Rajeshkumar S. Evaluation of the re-mineralization capacity of a gold nanoparticle-based dental varnish: An in vitro study. Journal of Conservative Dentistry. 2020 Jul 1; 23(4): 390.

[14]. Rajeshkumar S, Malarkodi C, Al Farraj DA, Elshikh MS, Roopan SM. Employing sulphated polysaccharide (fucoidan) as medium for gold nanoparticles preparation and its anticancer study against HepG2 cell lines. Materials Today Communications. 2021 Mar 1; 26: 101975.

[15]. Rajeshkumar S, Sherif MH, Malarkodi C, Ponnanikajamideen M, Arasu MV, Al-Dhabi NA, et al. Cytotoxicity behaviour of response surface model optimized gold nanoparticles by utilizing fucoidan extracted from padina tetrastromatica. Journal of Molecular Structure. 2021 Mar 15; 1228: 129440.

[16]. Kumar SA, Rajeshkumar S, Dinesh SS, George AM, Jain RK. Antimicrobial activity of silymarin mediated zinc oxide and hydroxy apatite nanoparticles against oral pathogens. Bioinformation. 2020; 16(11): 863-8.

[17]. Ganapathy D, Rajeshkumar S, Lakshmmi T. Nanobiotechnology in combating CoVid-19 Bioinformation. 2020; 16(11): 828-830.

[18]. Nasim I, Kumar SR, Vishnupriya V, Jabin Z. Cytotoxicity and anti-microbial analysis of silver and graphene oxide bio nanoparticles. Bioinformation. 2020; 16(11): 831-6.

[19]. Jackson K, Rajeshkumar S, Ezhilarasan D. Cytotoxic potentials of silibinin assisted silver nanoparticles on human colorectal HT-29 cancer cells Bioinformation. 2020; 16(11): 817-827.

[20]. Wu S, Rajeshkumar S, Madasamy M, Mahendran V. Green synthesis of copper nanoparticles using Cissus vitiginea and its antioxidant and antibacterial activity against urinary tract infection pathogens. Artif Cells Nanomed Biotechnol. 2020 Dec; 48(1): 1153-1158. PMID: 32924614.

[21]. Vikneshan M, Saravanakumar R, Mangaiyarkarasi R, Rajeshkumar S, Samuel SR, Suganya M, et al. Algal biomass as a source for novel oral nanoantimicrobial agent. Saudi J Biol Sci. 2020 Dec; 27(12): 3753-3758. PMID: 33304187.

[22]. Nandhini JT, Ezhilarasan D, Rajeshkumar S. An ecofriendly synthesized gold nanoparticles induces cytotoxicity via apoptosis in HepG2 cells. Environmental Toxicology. 2021 Jan; 36(1): 24-32. 